\title{
Serum Uric Acid Independently Predicts Cardiovascular Events in Advanced Nephropathy
}

\author{
Mehmet Kanbay ${ }^{a} \quad$ Mahmut llker Yilmaz $^{a} \quad$ Alper Sonmez $^{\mathrm{b}} \quad$ Yalcin Solak $^{\mathrm{c}}$ \\ Mutlu Saglam $^{d}$ Erdinc Cakir $^{\mathrm{e}}$ Hilmi Umut Unal $^{\mathrm{a}}$ Erol Arslan $^{\mathrm{a}}$ Samet Verim $^{\mathrm{d}}$ \\ Magdalena Madero ${ }^{f}$ Kayser Caglar ${ }^{a}$ Yusuf Oguz ${ }^{a} \quad$ Kim McFann $^{g}$ \\ Richard J. Johnson ${ }^{9}$

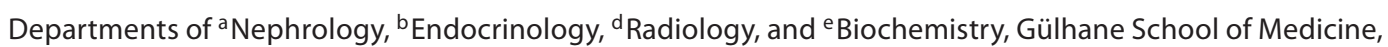 \\ Ankara, and ${ }^{\mathrm{C}}$ Division of Nephrology, Department of Medicine, Necmettin Erbakan University, Meram School of \\ Medicine, Konya, Turkey; ${ }^{\mathrm{f} D e p a r t m e n t}$ of Nephology, INC Ignacio Chavez, Mexico City, Mexico; ${ }^{9}$ Division of Renal \\ Diseases and Hypertension, University of Colorado, Denver, Colo., USA
}

\section{Key Words}

Uric acid · Chronic kidney disease $\cdot$ Cardiovascular disease

\begin{abstract}
Background: Chronic kidney disease (CKD) is associated with increased risk for cardiovascular (CV) disease and is also associated with elevated uric acid, which is emerging as a nontraditional CV risk factor. We therefore evaluated uric acid as a risk factor for $\mathrm{CV}$ disease in subjects presenting to nephrologists with CKD who were not on medications known to alter endothelial function. Methods: 303 subjects with stage 3-5 CKD were followed for a mean of 39 months (range 6-46) and assessed for fatal and nonfatal CV events. Hyperuricemia was defined as uric acid $>6.0 \mathrm{mg} / \mathrm{dl}$ for women and $>7.0 \mathrm{mg} / \mathrm{dl}$ for men. In addition to other CV risk factors, endothelial function (flow-mediated dilatation), inflammatory markers (hsCRP), and insulin resistance (HOMA index and fasting insulin levels) were included in the analysis. We evaluated the association between uric acid and flow-medi-
\end{abstract}

ated dilatation with linear regression. The impact of uric acid on composite CV events was assessed with Cox regression analysis. Results: Of a total of 303 patients, 89 had normouricemia and 214 had hyperuricemia. Both fatal (32 of 214 vs. 1 of 89 subjects) and combined fatal and nonfatal (100 of 214 vs. 13 of 89 subjects) CV events were more common in subjects with hyperuricemia compared with normal uric acid levels, and this was independent of estimated glomerular filtration rate, traditional CV risk factors including diabetes, hypertension and BMI, and nontraditional risk factors (hsCRP and endothelial function). The 46-month survival rate was $98.7 \%$ in the group with low uric acid compared to $85.8 \%$ in patients with high uric acid $(p=0.002)$. Conclusions: Hyperuricemia is an independent risk factor for CV events in subjects presenting with CKD who are not on medications known to alter endothelial function.

Copyright $\odot 2012$ S. Karger AG, Basel 


\section{Introduction}

Subjects with chronic kidney disease (CKD) are at increased risk for cardiovascular (CV) events and are more likely to die of $\mathrm{CV}$ disease than to progress to end-stage renal disease requiring dialysis [1]. There is convincing evidence that both traditional and nontraditional $\mathrm{CV}$ risk factors contribute to the increased risk of $\mathrm{CV}$ disease in CKD [2].

One potential risk factor for $\mathrm{CV}$ disease in subjects with CKD is uric acid. Uric acid is commonly elevated in subjects with CKD since its excretion is impaired in the setting of reduced renal function. In turn, there is accruing evidence that uric acid may have a role in driving inflammation and endothelial dysfunction in both subjects with normal [3-5] and impaired renal function [6, 7]. Furthermore, uric acid may have a role in hypertension, metabolic syndrome, and CKD itself $[8,9]$. Meta-analyses suggest that uric acid is an independent predictor of hypertension [10], type 2 diabetes [11], and stroke [12], with mixed reports for CV events [13, 14].

To date, only a few studies have examined if elevated uric acid predicts the development of CV disease in subjects with CKD. Madero et al. [15] reported that increasing uric acid levels conferred both increased CV mortality and all-cause mortality in subjects with CKD (stage 3 ) in the Modification of Diet in Renal Disease (MDRD) study. More recently, Goicoechea et al. [6] performed a pilot study in stage 3 CKD subjects in which patients were randomized to uric acid-lowering therapy (allopurinol) for 2 years. The allopurinol group had significantly fewer $\mathrm{CV}$ events compared to controls (12 vs. $26 \%$, respectively).

It is not yet known whether uric acid is an independent CV risk factor in CKD patients after controlling for closely interrelated confounding factors such as endothelial dysfunction, insulin resistance, and inflammation. Thus, we used a longitudinal design to evaluate the contribution of increased uric acid on composite CV outcomes in patients with moderate to severe CKD after controlling for both traditional and nontraditional CV risk factors.

\section{Methods}

Patients and Study Design

The aim of the study was to evaluate the role of increased serum uric acid as a risk factor for CV events in subjects with newly diagnosed CKD followed longitudinally. The study protocol was approved by the local institutional review board and written informed consent was obtained from all participants.
Between January 2005 and October 2009, 963 patients were referred to the Renal Unit of the Gulhane School of Medicine Medical Center, Ankara, Turkey, for initial evaluation of suspected CKD. Enrollment into the study required a diagnosis of CKD according to National Kidney Foundation K/DOQI Guidelines [16]. A substantial number of these subjects were being referred to nephrologists for the first time and were not on drugs that block the renin-angiotensin system (RAS). Furthermore, there appears to be less support that blockers of the RAS prevent the development of CKD in the nonproteinuric population $[17,18]$. Since inhibitors of the RAS, as well as statins, can alter endothelial function that might influence $\mathrm{CV}$ outcomes, we excluded subjects $(\mathrm{n}=495)$ if they were taking angiotensin-converting enzyme inhibitors $(n=182)$, angiotensin receptor blockers $(n=143)$ or statins $(\mathrm{n}=98)$. In addition, we also excluded subjects receiving EPO $(n=34)$ or supplemental vitamin pills $(n=38)$ or allopurinol $(\mathrm{n}=0)$ since EPO, allopurinol and vitamins $\mathrm{C}$ and $\mathrm{E}$ can also alter endothelial function [19-23]. Patients who were already on the aforementioned medications at the time of recruitment were excluded from the study because these medications have the potential to affect flow-mediated dilatation measurements. Once the patients were entered into the study and flow-mediated dilatation measurements were performed, the subjects were treated according to standard guidelines. Other exclusion criteria included acute infection and unwillingness to participate $(\mathrm{n}=34) .126$ eligible patients dropped out for the following reasons: lost to followup or transferred to other renal units $(n=79)$, or withdrawal of consent $(n=47)$. Stages of CKD were determined using estimated glomerular filtration rates (eGFR) which were calculated using the MDRD equation [24]. A total of 303 patients were included in the final analysis, consisting of 111 patients with stage 3, 86 patients with stage 4 , and 106 patients with stage 5 CKD. None of the patients with stage 5 CKD were on renal replacement therapy at the onset of the study.

All included patients were followed using time-to-event analysis until occurrence of fatal or nonfatal CV events (death, stroke, and myocardial infarction). Included patients were asked to visit outpatient nephrology clinic at regular intervals for determination of status of renal disease, any hospital admission and CV events. Patients who did not come for follow-up were contacted periodically via telephone and queried in terms of the same variables.

\section{Biochemical Analyses}

All blood samples were obtained from patients in the morning after $12 \mathrm{~h}$ of fasting for measurement of fasting plasma glucose (FPG), serum albumin, total serum cholesterol (TC), triglyceride (TG), high-density lipoprotein (HDL), and low-density lipoprotein (LDL) cholesterol. Total plasma cholesterol, TG and HDL cholesterol were measured by enzymatic colorimetric method with Olympus AU 600 autoanalyzer using reagents from Olympus Diagnostics, GmbH (Hamburg, Germany). LDL cholesterol was calculated by Friedewald's formula [25]. For the measurement of hsCRP, serum samples were diluted with a ratio of $1 / 100$ with the diluent solution. Calibrators, kit controls and serum samples were all added to each microwell with an incubation period of 30 min. After 3 washes, $100 \mu$ l enzyme conjugate (peroxidase labeled anti-CRP) was added to each microwell for an additional $15 \mathrm{~min}$ incubation at room temperature in the dark. The reaction was stopped with a stop solution and photometric measurement was 
Table 1. Demographic and clinical characteristics of the study groups according to serum uric acid

\begin{tabular}{|c|c|c|c|}
\hline & $\begin{array}{l}\text { Uric acid } \leq 7.0 \text { for males } \\
\text { and } \leq 6.0 \text { for females } \\
(n=89)\end{array}$ & $\begin{array}{l}\text { Uric acid }>7.0 \text { for males } \\
\text { and }>6.0 \text { for females } \\
(\mathrm{n}=214)\end{array}$ & $\mathrm{p}$ value \\
\hline Age, years & $47.5 \pm 12.8$ & $53.2 \pm 13.7$ & 0.0009 \\
\hline Male/female & $55 / 34(61.8 \%)$ & $96 / 118(44.86 \%)$ & 0.0072 \\
\hline Body mass index & $25.8 \pm 2.5$ & $25.4 \pm 2.9$ & 0.3140 \\
\hline \multicolumn{4}{|c|}{ History of cardiovascular disease, $\mathrm{n}$} \\
\hline No history & $75(84.27 \%)$ & $7(8.97 \%)$ & \multirow[t]{4}{*}{0.6977} \\
\hline Stroke & $2(2.25 \%)$ & $4(1.87 \%)$ & \\
\hline Peripheral vascular disease & $1(1.12 \%)$ & $3(1.40 \%)$ & \\
\hline Cardiovascular episode & $11(12.36 \%)$ & $38(17.76 \%)$ & \\
\hline Diabetes & $12(13.48 \%)$ & $59(27.57 \%)$ & 0.0084 \\
\hline Hypertension & $6(6.74 \%)$ & $46(21.5 \%)$ & 0.0019 \\
\hline \multicolumn{4}{|l|}{ Antihypertensive drugs } \\
\hline None & $83(93.26 \%)$ & $171(79.91 \%)$ & \multirow[t]{4}{*}{0.0391} \\
\hline Calcium channel blockers & $4(4.49 \%)$ & $32(14.95 \%)$ & \\
\hline$\beta$-Blockers & $1(1.12 \%)$ & $5(2.34 \%)$ & \\
\hline Loop diuretics & $1(1.12 \%)$ & $6(2.8 \%)$ & \\
\hline Smoking, current, $\mathrm{n}$ & $52(58.43 \%)$ & $114(5.27 \%)$ & 0.4115 \\
\hline
\end{tabular}

performed at the 450-nm wavelength. The amount of serum samples was calculated as $\mathrm{mg} / \mathrm{l}$ with a graphic that was made by noting the absorbance levels of the calibrators. The serum basal insulin value was determined by the coated tube method (DPC, USA). An insulin resistance score homeostasis model assessment-insulin resistance (HOMA-IR) was computed by the following formula [26]: HOMA-IR = Fasting glucose $(\mathrm{mg} / \mathrm{dl}) \times$ Immunoreactive insulin (IRI) $(\mu \mathrm{IU} / \mathrm{ml}) / 405$. Proteinuria was quantified using $24 \mathrm{~h}$ timed urine collection.

Arterial blood pressure was determined in the morning in all patients by a physician using three consecutive measurements, each after a 15-min resting period, with the mean values calculated for systolic and diastolic pressure.

\section{Assessment of Endothelial Function}

Endothelium-dependent vasodilatation [flow-mediated dilatation (FMD)] and endothelium-independent vasodilatation [nitroglycerine-mediated dilatation (NMD)] of the brachial artery were assessed noninvasively, using high-resolution ultrasound as described by Celermajer et al. [27]. The method for the vascular assessment met the criteria which were mentioned by the International Brachial Artery Reactivity Task Force [28]. Measurements were made by a single observer using an ATL 5000 ultrasound system (Advanced Technology Laboratories, Inc., Bothell, Wash., USA) with a $12-\mathrm{MHz}$ probe. The subjects remained at rest in the supine position for at least 15 min before the examination was initiated. The subject's arm was comfortably immobilized in the extended position to allow consistent recording of the brachial artery $2-4 \mathrm{~cm}$ above the antecubital fossa. Three adjacent measurements of end-diastolic brachial artery diameter were made from single 2-D frames. All ultrasound images were recorded on S-VHS videotape for subsequent blinded analysis. A pneumatic tourniquet was inflated to $200 \mathrm{~mm} \mathrm{Hg}$ with obliteration of the radial pulse. After 5 min the cuff was deflated. Flow measurements were made $60 \mathrm{~s}$ post-deflation. After a further $15 \mathrm{~min}$, measurements were repeated and again $3 \mathrm{~min}$ after administration of sublingual glyceryl trinitrate $400 \mu \mathrm{g}$ with oral route. The maximum FMD and NMD diameters were calculated as the average of the three consecutive maximum diameter measurements. The FMD and NMD were then calculated as the percent change in diameter compared with baseline resting diameters.

\section{Statistical Analyses}

All statistical analyses were performed by using SAS 9.2 statistical package (Cary, N.C., USA). Nonnormally distributed variables were expressed as median (range) and normally distributed variables were as mean $\pm S D$, as appropriate. A p value $<0.05$ was considered to be statistically significant. Between-group comparisons were assessed for nominal variables with the $\chi^{2}$ test, and by Kruskal-Wallis test (ANOVA) for the rest of variables. Data are presented in the form of hazard ratios (HR) and 95\% confidence intervals.

Uric acid was transformed into a categorical variable which was defined as high (uric acid $>6.0$ for women and $>7.0$ for men based on classical definitions of hyperuricemia) and low (uric acid $\leq 6.0$ for women and $\leq 7.0$ for men).

\section{Results}

The demographic and clinical characteristics of the subjects with high uric acid ( $>7.0$ for males and $>6.0$ for females) are depicted in table 1 . The biochemical data and endothelial function (FMD) values are shown in table 2. 
Table 2. Biochemical and vascular function according to serum uric acid

\begin{tabular}{lccr}
\hline & $\begin{array}{c}\text { Uric acid } \leq 7.0 \text { for males } \\
\text { and } \leq 6.0 \text { for females }(\mathrm{n}=89)\end{array}$ & $\begin{array}{l}\text { Uric acid }>7.0 \text { for males } \\
\text { and }>6.0 \text { for females }(\mathrm{n}=214)\end{array}$ & p value \\
\hline eGFR, ml/min & $39.0(4.0-58.0)$ & $16.0(2.0-57.0)$ & $<0.0001$ \\
Systolic BP, mm Hg & $133(113-170)$ & $135(110-189)$ & 0.0024 \\
Diastolic BP, mm Hg & $84(71-95)$ & $83.5(71-95)$ & 0.9208 \\
Serum albumin, g/dl & $4.0(3.0-5.2)$ & $4.0(3.0-4.8)$ & 0.7071 \\
Total cholesterol*, mg/dl & $202(157-245)$ & $200(159-249)$ & 0.0980 \\
Triglycerides*, mg/dl & $147(103-179)$ & $147.5(103-179)$ & 0.4683 \\
LDL, mg/dl & $128(89-175)$ & $125(81-176)$ & 0.0528 \\
HDL, mg/dl & $43(26-63)$ & $43(26-59)$ & 0.5401 \\
HOMA-IR index & $1.50(1.01-7.05)$ & $1.54(1.09-7.45)$ & 0.0160 \\
hsCRP, mg/l & $17(2-51)$ & $21(2-66)$ & 0.0003 \\
Glucose, mg/dl & $92(70-235)$ & $90.5(68-288)$ & 0.9345 \\
24-Hour proteinuria, g/day & $1.78(0.52-5.45)$ & $8.0(6.2-11.0)$ & 0.0890 \\
Uric acid, mg/dl & $5.8(2.7-7.0)$ & $12.8(10.0-13.8)$ & $<0.0001$ \\
NMD, \% & $13.0(10.8-13.8)$ & $6.2(4.0-9.0)$ & $<0.0001$ \\
FMD, \% & $7.2(4.3-9.2)$ & & $<0.0001$ \\
\hline
\end{tabular}

* Differences assessed by $\chi^{2}$ test for categorical variables and by Kruskal-Wallis test. Statistically significant if $\mathrm{p}<0.05$. To convert total cholesterol in $\mathrm{mg} / \mathrm{dl}$ to $\mathrm{mmol} / \mathrm{l}$, multiply by 0.02586 ; triglycerides in $\mathrm{mg} / \mathrm{dl}$ to $\mathrm{mmol} / \mathrm{l}$, multiply by 0.01129 .

Subjects with higher uric acid values tended to be female (55.14\%) and older, were more likely to have diabetes (27.6 vs. $13.5 \%, p=0.0084$ ), and were more likely to be hypertensive ( 21.5 vs. $6.74 \%, p=0.0019)$ than those with lower uric acid. Higher uric acid was associated with worse renal function $(\mathrm{p}<0.0001)$, higher SBP $(\mathrm{p}=0.0024)$, more insulin resistance $(\mathrm{p}=0.0160)$, higher $\mathrm{CRP}(\mathrm{p}=0.0003)$, lower NMD $(\mathrm{p}<0.0001)$, and decreased FMD $(\mathrm{p}<0.0001)$ (table 2).

\section{Prediction of CV Outcomes}

$\mathrm{CV}$ outcomes were determined beginning with the entry of the individual patient in the study onwards, with a mean follow-up period of 39 months (range 6-46). 37 patients died, 33 of which were due to $\mathrm{CV}$ causes. $\mathrm{CV}$ mortality was secondary to coronary heart disease $(n=16)$, sudden death $(n=7)$, stroke $(n=9)$ or complicated peripheral vascular disease $(n=1) .32$ of 214 patients with hyperuricemia died from CV disease versus 1 of 89 patients in the nonhyperuricemic group $(\mathrm{p}<0.001)$. Likewise, 68 of 214 hyperuricemic patients had nonfatal CV events versus 12 of 89 nonhyperuricemic controls ( $p<$ $0.001)$.

Univariate analysis showed that serum uric acid level and FMD significantly predicted fatal CV events. In multivariate Cox regression adjusting for age, gender, eGFR, diabetes status, smoking, hypertension, LDL, and SBP, serum uric acid, remained as a significant predictor of fatal CV events $(\mathrm{OR}=2.660$ (1.765-4.009), $\mathrm{p}<0.0001$; table 3). In a model also adjusting for HOMA, FMD, NMD, and CRP, elevated serum uric acid remained an independent risk factor for fatal CV events, while HOMA, FMD, NMD, and CRP levels did not (table 4).

A total of 113 fatal and nonfatal CV events occurred during the follow-up period. These included stroke ( $\mathrm{n}=$ $28)$, myocardial infarction ( $\mathrm{n}=77)$, and peripheral vascular disease $(n=8)$. The predictors for time-to-CV event were studied by uni- and multivariate Cox regression analyses. In multivariate Cox regression adjusting for classical risk factors, including age, gender, eGFR, diabetes status, smoking, hypertension, LDL, and SBP, elevated serum uric acid remained a significant predictor of combined fatal and nonfatal CV events $(\mathrm{OR}=1.317$ (1.101$1.575), p=0.0026$; table 5). In univariate analysis of nonclassical risk factors, serum uric acid, FMD, NMD, CRP and HOMA were significantly associated with development of combined fatal and nonfatal CV events (table 6). Notably, serum uric acid and CRP remained significantly associated with combined fatal and nonfatal CV events after adjusting for age, gender, eGFR, diabetes status, smoking, history of hypertension, LDL, SBP, FMD, NMD, CRP and HOMA (table 6). 
Table 3. Uni- and multivariate Cox regression of fatal events based on traditional risk factors

\begin{tabular}{llcrr}
\hline & Univariate analysis & p value & Multivariate analysis & p value \\
\hline Age, years & $0.993(0.968-1.018)$ & 0.5730 & $0.980(0.956-1.005)$ & 0.1210 \\
Male/female & $1.398(0.701-2.788)$ & 0.3417 & $1.420(0.658-3.064)$ & 0.3709 \\
eGFR, ml/min & $0.956(0.931-0.92)$ & 0.0010 & $1.008(0.977-1.040)$ & 0.6073 \\
Diabetes (yes/no) & $9.020(4.289-18.967)$ & $<0.0001$ & $7.106(3.272-15.429)$ & $<0.0001$ \\
Smoking (yes/no) & $3.454(1.605-7.431)$ & 0.0015 & $3.479(1.471-8.230)$ & 0.0045 \\
Hypertension (yes/no) & $1.855(0.862-3.993)$ & 0.1139 & $0.467(0.187-1.166)$ & 0.1030 \\
LDL, mg/dl & $0.998(0.979-1.018)$ & 0.8689 & $1.016(0.995-1.038)$ & 0.1344 \\
Systolic BP, mm Hg & $1.037(1.017-1.058)$ & 0.0003 & $1.020(0.997-1.044)$ & 0.0898 \\
Uric acid, mg/dl & $2.758(2.023-3.760)$ & $<0.0001$ & $2.660(1.765-4.009)$ & $<0.0001$ \\
\hline
\end{tabular}

Table 4. Uni- and multivariate Cox regression of fatal events based on both traditional and nontraditional risk factors

\begin{tabular}{llcrr}
\hline & Univariate analysis & p value & Multivariate analysis & p value \\
\hline Age, years & $0.993(0.968-1.018)$ & 0.5730 & $0.980(0.954-1.005)$ & 0.1181 \\
Male/female & $1.398(0.701-2.788)$ & 0.3417 & $1.295(0.591-2.840)$ & 0.5185 \\
eGFR, ml/min & $0.956(0.931-0.92)$ & 0.0010 & $1.013(0.977-1.050)$ & 0.4909 \\
Diabetes (yes/no) & $9.020(4.289-18.967)$ & $<0.0001$ & $7.759(3.155-19.081)$ & $<0.0001$ \\
Smoking (yes/no) & $3.454(1.605-7.431)$ & 0.0015 & $3.435(1.386-8.511)$ & 0.0077 \\
Hypertension (yes/no) & $1.855(0.862-3.993)$ & 0.1139 & $0.484(0.188-1.247)$ & 0.1328 \\
LDL, mg/dl & $0.998(0.979-1.018)$ & 0.8689 & $1.019(0.997-1.042)$ & 0.0984 \\
Systolic BP, mm Hg & $1.037(1.017-1.058)$ & 0.0003 & $1.017(0.993-1.042)$ & 0.1579 \\
Uric acid, mg/dl & $2.758(2.023-3.760)$ & $<0.0001$ & $2.819(1.783-4.458)$ & $<0.0001$ \\
HOMA-IR index & $1.248(0.993-1.568)$ & 0.0577 & $0.893(0.626-1.272)$ & 0.5296 \\
FMD, \% & $0.558(0.399-0.779)$ & 0.0006 & $0.758(0.470-1.225)$ & 0.2578 \\
NMD, \% & $0.889(0.593-1.332)$ & 0.5680 & $1.368(0.783-2.391)$ & 0.2709 \\
hsCRP, mg/l & $1.026(0.997-1.056)$ & 0.0792 & $0.990(0.951-1.032)$ & 0.6442 \\
\hline
\end{tabular}

Table 5. Uni- and multivariate Cox regression of fatal events and non-fatal events using traditional risk factors

\begin{tabular}{lcccr}
\hline & Univariate analysis & p value & Multivariate analysis & p value \\
\hline Age, years & $0.998(0.985-1.012)$ & 0.8086 & $0.998(0.985-1.012)$ & 0.7989 \\
Male/female & $1.182(0.816-1.714)$ & 0.3761 & $0.960(0.642-1.435)$ & 0.8418 \\
eGFR, ml/min & $0.962(0.949-0.975)$ & $<0.0001$ & $0.979(0.964-0.995)$ & 0.0103 \\
Diabetes (yes/no) & $3.943(2.712-5.734)$ & $<0.0001$ & $2.968(1.997-4.412)$ & $<0.0001$ \\
Smoking (yes/no) & $1.648(1.133-2.396)$ & 0.009 & $1.335(0.898-1.985)$ & 0.1533 \\
Hypertension (yes/no) & $2.170(1.434-3.284)$ & 0.0002 & $0.919(0.556-1.520)$ & 0.7432 \\
LDL, mg/dl & $0.997(0.986-1.008)$ & 0.5905 & $1.004(0.993-1.015)$ & 0.4530 \\
Systolic BP, mm Hg & $1.032(1.020-1.044)$ & $<0.0001$ & $1.018(1.006-1.031)$ & 0.0042 \\
Uric acid, mg/dl & $1.636(1.403-1.908)$ & $<0.0001$ & $1.317(1.101-1.575)$ & 0.0026 \\
\hline
\end{tabular}


Table 6. Uni- and multivariate Cox regression of fatal events and non-fatal events of traditional and nontraditional risk factors

\begin{tabular}{llccr}
\hline & Crude analysis & p value & Model 1 & p value \\
\hline Age, years & $0.998(0.985-1.012)$ & 0.8086 & $1.002(0.988-1.016)$ & 0.7950 \\
Male/female & $1.182(0.816-1.714)$ & 0.3761 & $0.982(0.653-1.478)$ & 0.9310 \\
eGFR, ml/min & $0.962(0.949-0.975)$ & $<0.0001$ & $0.988(0.971-1.006)$ & 0.1936 \\
Diabetes (yes/no) & $3.943(2.712-5.734)$ & $<0.0001$ & $2.654(1.694-4.158)$ & $<0.0001$ \\
Smoking (yes/no) & $1.648(1.133-2.396)$ & 0.009 & $1.331(0.885-2.000)$ & 0.1696 \\
Hypertension (yes/no) & $2.170(1.434-3.284)$ & 0.0002 & $0.972(0.582-1.621)$ & 0.9123 \\
LDL, mg/dl & $0.997(0.986-1.008)$ & 0.5905 & $1.005(0.994-1.017)$ & 0.3330 \\
Systolic BP, mm Hg & $1.032(1.020-1.044)$ & $<0.0001$ & $1.018(1.005-1.032)$ & 0.0069 \\
Uric acid, mg/dl & $1.636(1.403-1.908)$ & $<0.0001$ & $1.294(1.075-1.558)$ & 0.0065 \\
HOMA-IR index & $1.310(1.151-1.492)$ & $<0.0001$ & $1.105(0.925-1.319)$ & 0.2702 \\
FMD, \% & $0.593(0.497-0.709)$ & $<0.0001$ & $0.809(0.631-1.038)$ & 0.0954 \\
NMD, \% & $0.788(0.628-0.989)$ & 0.0396 & $1.191(0.906-1.566)$ & 0.2103 \\
hsCRP, mg/l & $1.035(1.019-1.052)$ & $<0.0001$ & $1.026(1.006-1.047)$ & 0.0100 \\
\hline
\end{tabular}

Both fatal and nonfatal CV events tended to occur more commonly in patients with stage 5 CKD compared with patients with stage 3 and 4 CKD. 16 out of 33 (48.5\%) fatal events and 33 out of 80 (41.3\%) nonfatal events took place in subjects with stage $5 \mathrm{CKD}$.

\section{Survival Analysis}

Every 1-mg/dl increase in serum uric acid level increased the likelihood of a fatal or nonfatal CV event by $32 \%(\mathrm{HR}=1.32(1.101-1.575), \mathrm{p}<0.0001)$ and the likelihood of a fatal event by $266 \%$ ( $\mathrm{HR}=2.66(1.77-4.01), \mathrm{p}<$ $0.0001)$ by Cox regression when adjusted for covariates.

\section{Discussion}

The main finding of this study was that uric acid could predict fatal and nonfatal CV events independent of impaired endothelial function and other potential confounders in patients with moderate to severe CKD who were not on medications known to alter endothelial function. These data extend the results of Madero et al. [15] and are in alignment with the pilot interventional data by Goicoechea et al. [6]. Together, these data suggest that increased serum uric acid level may be an important risk factor for CV disease in subjects with CKD and emphasize the requirement of performing an intervention trial to determine if lowering uric acid would reduce $\mathrm{CV}$ events in this population.

The study was designed to evaluate the role of serum uric acid as an independent $\mathrm{CV}$ risk factor in subjects with moderate to severe CKD. The initial evaluation included measurements of endothelial function (FMD) and inflammation (hsCRP). To have accurate measurements of the endothelial function associated with the CKD, it was important to perform the analysis in subjects in patient presenting with CKD who were not already on medications that could alter endothelial function, such as statins, RAS blockers, vitamin C and E, or allopurinol. This was especially important as uric acid may act to induce CV disease by altering endothelial function or stimulating the renin-angiotensin-aldosterone system [2931]. As such, subjects receiving these drugs or other confounding drugs at the onset of the study were excluded to avoid potential confounding effects on endothelial dysfunction and inflammation. However, once the initial investigations were performed, patients were allowed to receive these agents as indicated.

The most striking finding was that serum uric acid levels at study entry could significantly predict development of future CV events over the subsequent 2-3 years. Most of the fatal and nonfatal CV events developed in subjects with elevated uric acid levels. Furthermore, these results were independent of inflammation, endothelial function, or traditional $\mathrm{CV}$ risk factors such as insulin resistance, eGFR, or increased blood pressure. These results suggest that uric acid may be a true and easily measureable risk factor for prediction of $\mathrm{CV}$ events in patient with CKD.

There are several potential mechanisms by which uric acid might confer $\mathrm{CV}$ risk. For example, experimental studies suggest that uric acid may stimulate vasoconstric- 
tion by activation of the RAS [30], thromboxane [32], endothelin [33] and oxidants; uric acid may also have effects on endothelial function. Uric acid has also been found to activate inflammatory pathways [3], in part by stimulating NF-кB [34]. Uric acid has direct effects on blood vessels [29] and the heart [35].

Both insulin resistance and hyperinsulinemia are independently associated with an increased prevalence of CKD [36]. Fliser et al. [37] showed that insulin resistance and concomitant hyperinsulinemia are present in early stages of CKD, even in patients with GFR within the normal range, irrespective of the type of renal disease. In subjects with normal renal function, hyperinsulinemia has been reported to be a risk factor for CV events, which is due in part to its association with obesity, hypertension and dyslipidemia [38, 39]. In our study, hyperinsulinemia was a risk factor for $\mathrm{CV}$ events by univariate analysis, but this association was lost when multivariate analysis was performed.

A primary limitation of our study is that we excluded subjects at the initial evaluation who were on medications known to alter endothelial function. As such, our finding of uric acid as a major risk factor for $\mathrm{CV}$ disease is primarily for subjects presenting with $\mathrm{CKD}$ who are not on $\mathrm{ACE}$ inhibitors or statins. However, following the initial evaluation, many of our subjects were placed on blockers of the RAS by their nephrologists. Importantly, the serum uric acid at presentation was found to carry major risk for subsequent $\mathrm{CV}$ disease in these patients.

In conclusion, we demonstrate a strong association of elevated serum uric acid with CV hard endpoints (both fatal and nonfatal CV events) independent of traditional risk factors, endothelial dysfunction, insulin resistance and inflammation. Longitudinal studies investigating the effect of uric acid-lowering therapies on CV outcomes should clarify this issue further.

\section{Acknowledgement}

Kim McFann is supported in part by NIH/NCRR Colorado CTSI Grant UL1 RR025780.

\section{Disclosure Statement}

Dr. R.J. Johnson has patent applications related to lowering uric acid as a means to treat hypertension, reduce the frequency of diabetes, and treat fatty liver. The other authors have no conflicts of interest to disclose.

\section{References}

1 Schiffrin EL, Lipman ML, Mann JF: Chronic kidney disease: effects on the cardiovascular system. Circulation 2007;116:85-97.

$\checkmark 2$ Rodriguez-Iturbe B, Correa-Rotter R: Cardiovascular risk factors and prevention of cardiovascular disease in patients with chronic renal disease. Expert Opin Pharmacother 2010;11:2687-2698.

-3 Kanbay M, Ozkara A, Selcoki Y, Isik B, Turgut F, Bavbek N, Uz E, Akcay A, Yigitoglu R, Covic A: Effect of treatment of hyperuricemia with allopurinol on blood pressure, creatinine clearence, and proteinuria in patients with normal renal functions. Int Urol Nephrol 2007;39:1227-1233.

-4 Mercuro G, Vitale C, Cerquetani E, Zoncu S, Deidda M, Fini M, Rosano GM: Effect of hyperuricemia upon endothelial function in patients at increased cardiovascular risk. Am J Cardiol 2004;94:932-935.

5 Melendez-Ramirez G, Perez-Mendez O, Lopez-Osorio C, Kuri-Alfaro J, Espinola-Zavaleta $\mathrm{N}$ : Effect of the treatment with allopurinol on the endothelial function in patients with hyperuricemia. Endocr Res 2012;37:16.
6 Goicoechea M, de Vinuesa SG, Verdalles U, Ruiz-Caro C, Ampuero J, Rincon A, Arroyo D, Luno J: Effect of allopurinol in chronic kidney disease progression and cardiovascular risk. Clin J Am Soc Nephrol 2010;5:13881393.

-7 Kanbay M, Yilmaz MI, Sonmez A, Turgut F, Saglam M, Cakir E, Yenicesu M, Covic A, Jalal D, Johnson RJ: Serum uric acid level and endothelial dysfunction in patients with nondiabetic chronic kidney disease. Am J Nephrol 2011;33:298-304.

-8 Feig DI, Kang DH, Johnson RJ: Uric acid and cardiovascular risk. N Engl J Med 2008;359: 1811-1821.

-9 Feig DI: Uric acid: a novel mediator and marker of risk in chronic kidney disease? Curr Opin Nephrol Hypertens 2009; 18:526530.

-10 Grayson PC, Kim SY, Lavalley M, Choi HK: Hyperuricemia and incident hypertension: a systematic review and meta-analysis. Arthritis Care Res (Hoboken) 2011;63:102-110.

11 Kodama S, Saito K, Yachi Y, Asumi M, Sugawara A, Totsuka K, Saito A, Sone H: Association between serum uric acid and development of type 2 diabetes. Diabetes Care 2009; 32:1737-1742.
12 Kim SY, Guevara JP, Kim KM, Choi HK, Heitjan DF, Albert DA: Hyperuricemia and risk of stroke: a systematic review and metaanalysis. Arthritis Rheum 2009;61:885-892.

13 Kim SY, Guevara JP, Kim KM, Choi HK, Heitjan DF, Albert DA: Hyperuricemia and coronary heart disease: a systematic review and meta-analysis. Arthritis Care Res (Hoboken) 2010;62:170-180

14 Wheeler JG, Juzwishin KD, Eiriksdottir G, Gudnason V, Danesh J: Serum uric acid and coronary heart disease in 9,458 incident cases and 155,084 controls: prospective study and meta-analysis. PLoS Med 2005;2:e76.

15 Madero M, Sarnak MJ, Wang X, Greene T, Beck GJ, Kusek JW, Collins AJ, Levey AS, Menon V: Uric acid and long-term outcomes in CKD. Am J Kidney Dis 2009;53:796-803.

- $16 \mathrm{~K} / \mathrm{DOQI}$ clinical practice guidelines for bone metabolism and disease in chronic kidney disease. Am J Kidney Dis 2003;42:S1S201.

17 Daien V, Duny Y, Ribstein J, du Cailar G, Mimran A, Villain M, Daures JP, Fesler P: Treatment of hypertension with renin-angiotensin system inhibitors and renal dysfunction: a systematic review and meta-analysis. Am J Hypertens 2012;25:126-132. 
18 Casas JP, Chua W, Loukogeorgakis S, Vallance P, Smeeth L, Hingorani AD, MacAllister RJ: Effect of inhibitors of the renin-angiotensin system and other antihypertensive drugs on renal outcomes: systematic review and meta-analysis. Lancet 2005;366:20262033.

-19 Dogra GK, Watts GF, Herrmann S, Thomas MA, Irish AB: Statin therapy improves brachial artery endothelial function in nephrotic syndrome. Kidney Int 2002;62:550-557.

-20 Varin R, Mulder P, Tamion F, Richard V, Henry JP, Lallemand F, Lerebours G, Thuillez C: Improvement of endothelial function by chronic angiotensin-converting enzyme inhibition in heart failure: role of nitric oxide, prostanoids, oxidant stress, and bradykinin. Circulation 2000;102:351-356.

-21 Plantinga Y, Ghiadoni L, Magagna A, Giannarelli C, Franzoni F, Taddei S, Salvetti A: Supplementation with vitamins $\mathrm{C}$ and $\mathrm{E}$ improves arterial stiffness and endothelial function in essential hypertensive patients. Am J Hypertens 2007;20:392-397.

-22 Wang XQ, Vaziri ND: Erythropoietin depresses nitric oxide synthase expression by human endothelial cells. Hypertension 1999; 33:894-899.

-23 George J, Carr E, Davies J, Belch JJ, Struthers A: High-dose allopurinol improves endothelial function by profoundly reducing vascular oxidative stress and not by lowering uric acid. Circulation 2006;114:2508-2516.

-24 Levey AS, Bosch JP, Lewis JB, Greene T, Rogers N, Roth D: A more accurate method to estimate glomerular filtration rate from serum creatinine: a new prediction equation. Modification of Diet in Renal Disease Study Group. Ann Intern Med 1999;130:461-470.

-25 Friedewald WT, Levy RI, Fredrickson DS: Estimation of the concentration of low-density lipoprotein cholesterol in plasma, without use of the preparative ultracentrifuge. Clin Chem 1972;18:499-502.
26 Matthews DR, Hosker JP, Rudenski AS, Naylor BA, Treacher DF, Turner RC: Homeostasis model assessment: insulin resistance and $\beta$-cell function from fasting plasma glucose and insulin concentrations in man. Diabetologia 1985;28:412-419.

$\checkmark 27$ Celermajer DS, Sorensen KE, Gooch VM, Spiegelhalter DJ, Miller OI, Sullivan ID, Lloyd JK, Deanfield JE: Non-invasive detection of endothelial dysfunction in children and adults at risk of atherosclerosis. Lancet 1992;340:1111-1115.

28 Corretti MC, Anderson TJ, Benjamin EJ, Celermajer D, Charbonneau F, Creager MA, Deanfield J, Drexler H, Gerhard-Herman M, Herrington D, Vallance P, Vita J, Vogel R: Guidelines for the ultrasound assessment of endothelial-dependent flow-mediated vasodilation of the brachial artery: a report of the International Brachial Artery Reactivity Task Force. J Am Coll Cardiol 2002;39:257265.

29 Kang DH, Park SK, Lee IK, Johnson RJ: Uric acid-induced C-reactive protein expression: implication on cell proliferation and nitric oxide production of human vascular cells. J Am Soc Nephrol 2005;16:3553-3562.

30 Mazzali M, Hughes J, Kim YG, Jefferson JA, Kang DH, Gordon KL, Lan HY, Kivlighn S, Johnson RJ: Elevated uric acid increases blood pressure in the rat by a novel crystalindependent mechanism. Hypertension 2001;38:1101-1106.

31 Khosla UM, Zharikov S, Finch JL, Nakagawa T, Roncal C, Mu W, Krotova K, Block ER, Prabhakar S, Johnson RJ: Hyperuricemia induces endothelial dysfunction. Kidney Int 2005;67:1739-1742.

32 Kang DH, Nakagawa T, Feng L, Watanabe S, Han L, Mazzali M, Truong L, Harris R, Johnson RJ: A role for uric acid in the progression of renal disease. J Am Soc Nephrol 2002;13: 2888-2897.
33 Chao HH, Liu JC, Lin JW, Chen CH, Wu CH, Cheng TH: Uric acid stimulates endothelin-1 gene expression associated with NADPH oxidase in human aortic smooth muscle cells. Acta Pharmacol Sin 2008;29:1301-1312.

>34 Kanellis J, Watanabe S, Li JH, Kang DH, Li P, Nakagawa T, Wamsley A, Sheikh-Hamad D, Lan HY, Feng L, Johnson RJ: Uric acid stimulates monocyte chemoattractant protein-1 production in vascular smooth muscle cells via mitogen-activated protein kinase and cyclooxygenase-2. Hypertension 2003;41: 1287-1293.

35 Cheng TH, Lin JW, Chao HH, Chen YL, Chen $\mathrm{CH}$, Chan P, Liu JC: Uric acid activates extracellular signal-regulated kinases and thereafter endothelin-1 expression in rat cardiac fibroblasts. Int J Cardiol 2010;139:4249.

36 Sarafidis PA, Ruilope LM: Insulin resistance, hyperinsulinemia, and renal injury: mechanisms and implications. Am J Nephrol 2006; 26:232-244.

$>37$ Fliser D, Pacini G, Engelleiter R, KautzkyWiller A, Prager R, Franek E, Ritz E: Insulin resistance and hyperinsulinemia are already present in patients with incipient renal disease. Kidney Int 1998;53:1343-1347.

38 Garcia RG, Rincon MY, Arenas WD, Silva SY, Reyes LM, Ruiz SL, Ramirez F, Camacho PA, Luengas C, Saaibi JF, Balestrini S, Morillo C, Lopez-Jaramillo P: Hyperinsulinemia is a predictor of new cardiovascular events in Colombian patients with a first myocardial infarction. Int J Cardiol 2011; 148:85-90.

39 Lakka HM, Lakka TA, Tuomilehto J, Sivenius J, Salonen JT: Hyperinsulinemia and the risk of cardiovascular death and acute coronary and cerebrovascular events in men: the Kuopio Ischaemic Heart Disease Risk Factor Study. Arch Intern Med 2000;160:11601168 . 